\title{
Opportunities and Constraints in Implementing Innovation Marketing in the Urban Passenger Traffic
}

\begin{abstract}
Submitted 17/05/20, 1 st revision 13/06/20, 2nd revision 12/07/20, accepted 30/07/20
\author{
Galazova S.S. ${ }^{1}$, Kalieva O.M. ${ }^{2}$, Luzhnova N.V. ${ }^{3}$, Karelin N.V. ${ }^{4}$
}

Abstract:

Purpose: This article is aimed at exploring the possibilities and limitations of using innovation marketing tools in the field of urban passenger traffic.

Design/Methodology/Approach: The expansion of urbanization processes, the development of competition in the urban passenger transportation market, an increase in passenger demand for the quality of services provided by municipal and commercial carriers require the introduction of a wide range of innovations. The substantiation of the importance, determination of the possibilities and limitations of the introduction of innovation marketing for the improvement of urban passenger transportation is presented in this article. The methodological basis of the research relies on a systematic approach and factor analysis which provide the comprehensive study of characteristics of the urban passenger transportation market as well as the the identification of opportunities and barriers in the process of implementing the innovation marketing tools.
\end{abstract}

Findings: The study made possible clarifying the sense and features of innovation marketing. The authors characterized the conjuncture of the urban passenger transportation market, identified the positive opportunities and negative factors affecting the introduction of tools of the innovation marketing complex into the activities of organizations in the urban passenger transportation market.

Practical implications: In practice, the results will help determining the directions of introducing the innovation marketing tools into the activities of organizations in the urban passenger transportation market.

Originality/value: The study has original results clarifying the conditions for introducing innovation marketing into the activities of organizations in the urban passenger transportation market.

Keywords: Innovation marketing, market conditions, urban passenger transportation, opportunities and barriers of innovation marketing.

JEL Code: M31, M39, O39.

Paper type: Research paper.

\footnotetext{
${ }^{1}$ D.Sc in Economics, Professor, Khetagurov North Ossetian State University, Vladikavkaz, Russian Federation

${ }^{2}$ D.Sc. in Economics, Professor, Orenburg State University, Orenburg, Russian Federation, kaf_mark@mail.ru

${ }^{3}$ Ph.D. in Economics, Associate Professor, Orenburg State University, Orenburg, Russian Federation, nat_val@inbox.ru

${ }^{4}$ Postgraduate, Orenburg State University, Orenburg, Russian Federation, kaf_mark@mail.ru
} 


\section{Introduction}

Now, the main advantage of an organization is a quick response to changing consumer needs and bringing new products or services to market. It is the innovation marketing toolkit that allows quickly and more efficiently identifying unmet needs or untapped market niches, adapting an innovative product or service to the requirements of the market, and also promoting the innovation to the market to convert it into a well-known product or service.

The transport issue has become one of the main problems in cities, many city dwellers suffer from this, which is why government bodies are applying many measures to solve the problems of environmental protection of the urban population and the development of their life quality by encouraging the use of public transport instead of personal: travel to the city center in different days for cars with even or odd license plates, prohibited parking spaces, higher vehicle tax rates and higher fuel prices, limited parking spaces, higher parking fees. This demotivates consumers. In addition to traditional policies, it is necessary to apply new approaches to the development of the urban passenger transport sector, one of which is the marketing of innovations.

\section{Materials and Methods}

Innovation marketing is a system of activities aimed at researching and promoting an innovative product to the market (Ivanitskaya, 2014). According to Ivanchenko, (2014), innovation marketing is a marketing activity for the creation and promotion of goods, services, projects with significantly new properties. Matkovskaya (2010) considers innovation marketing as an opportunity to commercialize innovation in order to bring economic benefits to the person implementing it. Despite the large amount of research devoted to innovation and marketing of innovations, the features of the application of innovation marketing in the urban passenger transportation market require further study. This study utilized a systematic approach and factor analysis.

\section{Results}

The authors clarified the definition of innovation marketing as a purposeful activity to identify unmet consumer needs, study the possibilities of developing and commercializing competitive innovations and promoting them in the market in order to obtain economic benefits (Kalieva and Frolova, 2012).

The economic content of innovation marketing lies in the fact that decision-making in the implementation of the innovation policy of enterprises is associated with risks, while the use of marketing tools makes possible justifying innovative solutions, minimizing lost profits and maximizing profits in market conditions. 
Innovation Marketing in urban passenger transportation, according to the authors, is an activity aimed at developing and promoting innovations in the field of urban civil traffic services that have a competitive advantage in the passenger transportation market in order to achieve the satisfaction and economic benefits of all participants in urban road traffic.

New products, technologies, ways of promoting services in the field of urban transport were identified as the object of innovation marketing in urban passenger transportation. The subject is the compliance of new products and technologies with the needs of the passenger transportation market. To implement the concept of innovation marketing in urban passenger transportation, it is necessary to apply the following functions of innovation marketing adapted for use in the field of passenger transportation: research (studying the needs, expectations, perceptions of the target audience of urban passenger transportation, searching for innovation), predictive (the study and prediction of possible reactions of the target audience from the introduction of promising innovations in the near future), informational (collection of information about innovative products and technologies, taking into account their demand from the target audience, carriers, higher organizations and investors), organizational (combination of managerial, legislative, economic, production and other aspects for the implementation of innovative projects in urban passenger transportation), advertising (development of a comprehensive system for promoting innovations in the field of urban passenger transportation), practical (ensuring the effective implementation of innovative projects in the field of urban passenger transportation).

Based on the research findings, the characteristics of the urban passenger transportation market were determined:

- dynamism and instability of supply and demand. Urban public transport includes a mix of alternative types of transport, different types of passengers (eg students, workers, vacationers) and passengers with different travel purposes, travel frequencies and travel times. The availability of various modes of transport makes possible for passengers switching between these types of transport. In such an environment, the demand for public transport is dynamic and volatile. The supply could also change dramatically due to technical malfunctions of vehicles, an ambiguous situation on the city's roads or due to the short-sighted policies of commercial and municipal transport enterprises. However, it can be said that supply and demand are generally in equilibrium;

- a large dependence of the demand for urban passenger transport is on the time of day, week, year. In general, the main demand is in the morning and evening. During rush hour, demand mainly comes from workers and students, the rest of the time from shopping mall buyers and vacationers. In the spring - summer - autumn period, the demand for country and suburban routes increases, the demand for urban routes decreases due to the use of personal transport during the warm season and the period of summer holidays and vacations; 
- a variety of goals and expectations of urban passenger transport consumers, which affects the complexity of the parameters for assessing the quality of services provided by passengers by urban passenger transport. Different types of users have different expectations for public transport services based on the time and purpose of the trip. The time and purpose of the trip also affect the level of expectations in different ways and, in turn, the demand. Using public transport for work and leisure at different times of the day may require a different level of service quality (for example, travel speed for commuting or an interesting route for recreation);

- the presence of latent competition between cars and public transport, especially in terms of pricing and environmental issues. Most of these problems fall on the local authorities, from which the population expects not only to eliminate environmental problems associated with air pollution, but also to develop the infrastructure necessary for comfortable travel around the city;

- high costs of innovative transformation of passenger transport to meet the everincreasing needs and expectations of passengers regarding the quality of urban passenger transport. Due to the lack of cardinal innovative solutions to completely change the urban transportation system, many residents completely refuse to travel by public transport due to low comfort. Today, the priority issue is to increase the number of passengers using public transport services. This is essential for operational efficiency, customer satisfaction and profitability;

- a limited number of vehicles in terms of the capacity of urban transport routes and the high cost of innovative vehicles (electric buses, unmanned vehicles), which, for objective reasons, is a barrier to increasing the number of small class buses and requires the introduction of large buses on routes for transportation of more passengers at once.

Opportunities for implementing innovation marketing tools in the urban passenger transport system are:

- an urgent need to solve environmental problems by reducing the use of personal vehicles instead of increasing the demand for public transportation in the city. Therefore, the main task of innovation marketing in urban passenger transport is how to transfer private car users to public transport in the current problematic environment. If public transport services are provided by more than one party, and the passenger has more options to choose from, then the market will be competitive, and passengers will choose more profitable options from the offer. Innovation marketing should ensure greater consumer value of public transport for citizens; - digitalization of the economy with the introduction of intelligent transport systems that make it possible to optimally manage urban traffic flows while achieving a balance of goals for the functioning of the urban transport system, the development of municipal and commercial carrier organizations and meeting the needs of passengers. The development of artificial intelligence, the introduction of digital platforms for traffic management, and the increase in the digital skills of urban residents provide the basis for the introduction of innovation marketing tools using digital resources; 
- the competition in the urban passenger transportation market due to the presence of carriers of different organizational and legal forms and scale of activity. At the same time, the routes of vehicles could be parallel on some sections of the roads, which increases their competition. Some freedom of commercial carriers in pricing and promoting their services also acts as an opportunity for innovation marketing;

- the growing demand for urban passenger transport services due to the increase in the urban population and the increasing popularity of conscious consumption of products and services. Urban passenger transport services are products from a marketing point of view that are supplied by a municipal or commercial transport to meet specific human needs. They have their own sense, price, are offered in a specific location and are subject to promotion to encourage more and more people to use them.

Based on the results of the study, the following barriers limiting the process of introducing innovation marketing tools into the activities of enterprises in the field of urban passenger transportation were identified:

- resource intensity of innovations - the need to invest large monetary, material and intellectual resources in prototypes of modern vehicles and intelligent software;

- the duration of the stages of diffusion and adaptation of innovations - the initial stage of the life cycle of innovations in the field of urban passenger transport can take several years due to the need to conduct a large number of tests to ensure the complete safety of transport innovations for passengers;

- psychological consumers' distrust of innovations - a large share of conservativeminded passengers among the total number of citizens using urban public transport may have doubts about innovations or even reject them at the initial stage;

- the impossibility of a radical change in the urban transport system - the linking of transport infrastructure facilities to the historically established layout of the urban road network, which makes it impossible to completely rebuild the road network even for more optimal use of all resources.

\section{Discussion}

The need for marketing to drive innovation in public transport has been studied for a long time. A study (Hovell and Jones, 1975) looks at marketing functions as well as personnel marketing approaches in some UK public transport organizations. The authors pointed out that urban passenger transport organizations paid very little or no attention to marketing functions, did not hire enough marketers, and ignored the marketing aspect in the decision-making process to innovate.

However, innovation marketing is ignored both in research and in the practice of urban passenger transport enterprises. Analysis of the activities of civil transport organizations indicates that transport companies do not conduct research of market and customer needs. Among the main reasons for this is the form of company's incorporation - state, municipal or with a high share of participation of state 
authorities in the process of choosing routes, determining tariffs and specifics of urban transportation.

The scientific papers offer some partial solutions to the problem of public transport, but these usually involve non-marketing approaches. For example, in their study on application in several European countries, Bonnel and Chausse (2000) argued that sufficient supply alone is not sufficient to address the problem of public transport, as a comprehensive and consistent approach is needed, indicating that an approach to this the problem has mainly focused on increasing supply to better meet demand. Scientists argued that pricing is crucial in determining the demand for transportation, since the inability to take into account the specifics of pricing (for example, the phenomenon of subsidizing tariffs on municipal routes by government authorities) negatively affects the development of the urban passenger transport system. We believe that an integrated marketing approach to urban public transport is poorly presented in the literature, there are many studies indicating the role of distribution (for example, route selection and area coverage) in public transport services. However, research is not primarily done by marketers, so, for example, the role of promotion in the success of urban passenger transport organizations is rarely examined.

Consumer preferences are of particular importance to marketing efforts to drive innovation, and public transport is no exception. To increase the use of public transport, much more attention should be paid to passenger behavior than public transport infrastructure in cities, because the use of public transport is not only a decision based on technical or physical conditions, but also a decision based on the behavioral characteristics of passengers. There are many studies by foreign scientists (Murray, 2001; Paine et al., 1967; Golob, Canty and Gustafson, 1972), which focus on issues such as customer preferences and factors influencing consumer decisionmaking when choosing a type of vehicle when moving around the city.

In such a matter, the wrong assumption is that public transport usage increases when a large number of vehicles are available, given that current road infrastructure, income levels and tariff levels remain the same. This has not been proven since the problem is more behavioral than technical. Even the high comfort and low cost of public transport may not solve the problem of choosing this type of travel by citizens if their expectations are not taken into account. For example, a private car is more likely to be used by a high-income population, even with sufficient public transport available.

\section{Conclusion}

Thus, passenger transport is an integral part of the life of a modern city, aimed at meeting the needs of the population to move in the urban environment. The constantly changing vital needs of the city largely determine the development of passenger traffic in a new direction. The features of the urban passenger 
transportation market presented in this article include: the dynamism and instability of demand and supply, a large dependence of demand on the time of use of transport, a variety of goals for consumers of urban passenger transportation services, the dependence of supply on the transport network capacity and the presence of hidden competition with private vehicles directly affect the identified limitations of the introduction of marketing of innovations - the resource intensity of innovations, the duration of the stages of diffusion and adaptation of innovations, psychological distrust of innovations on the part of potential consumers of transport passenger services, the impossibility of a radical change in the urban transport system.

But the prospects for introducing innovation marketing tools are justified by the following opportunities: an urgent need to solve environmental problems, digitalization of the economy with the introduction of intelligent transport systems, competition in the urban passenger transportation market due to the carriers of different organizational and legal forms and scale of activity and the growing demand for civil transport due to the constant increase in the urban population.

It is also substantiated that the use of tools of the innovation marketing complex in the activities of municipal and commercial transport organizations in the field of urban passenger transportation should increase the demand for movement of the city's population using public transport, improve the environmental situation in cities, save budget funds due to the absence of the need to change the road infrastructure for passenger car traffic, as well as increase passenger satisfaction with the provision of urban passenger transportation services.

\section{References:}

Bonnel, P., Chausse, A. 2000. Urban Travel: Competition and Pricing. Transport Reviews, 385-401

Golob, T.F., Canty, E.T., Gustafson, R.L. 1972. An Analysis of Consumer Preferences for a Public Transportation System. Transportation Research, 1(6)

Hovell, P.J., Jones, W.H. 1975. Some Organizational Problems Facing Urban Passenger Transport Marketing. European Journal of Marketing, 2(9), 117-128.

Ivanchenko, O.P., Belotserkovskaya, N.V. 2014. Marketing innovations: approaches, types, content and implementation. Bulletin of OSU, 4, 207.

Ivanitskaya, A.E. 2014. A functional approach to the management of innovative activities of an enterprise. Ph.D. thesis, Vladimir, 29.

Kalieva, O.M., Frolova, O.V. 2012. Marketing of innovations as a tool for successful business. Bulletin of OSU, 13, 175.

Matkovskaya, Y.S. 2010. The problem of commercialization of innovative technologies in Russia and the directions of its solution. National interests: priorities and security, 3 (60), 35-45.

Murray, A.T. 2001. Strategic Analysis of Public Transport Coverage. Socio-Economic, Planning Sciences, 175-188.

Paine, F.J., Nash, A.N., Hille, S.T., Brunner, G.A. 1967. Consumer Conceived Attributes of Transportation. Department of Business Administration, University of Maryland. 